\title{
Anatomical and Histochemical Factors Associated with Bronzing Development in Strawberry Fruit
}

\author{
Vito S. Polito, ${ }^{1}$ Kirk D. Larson, ${ }^{2}$ and Katherine Pinney ${ }^{3}$ \\ Department of Pomology, University of California, Davis, CA 95616-8683
}

\begin{abstract}
AdDitional INDEX WORDs. epidermis, Fragaria $\times$ ananassa, parenchyma, pectin, phenolics, suberization, sunscald
Abstract. Bronzing of strawberry (Fragaria $\times$ ananassa Duchesne) fruit that is not the result of arthropod feeding or chemical spray application occurs frequently in California's central coast strawberry production region from late spring through midsummer, a period characterized by relatively high temperature, low relative humidity, and high solar irradiance. The cause of this phenomenon is not known, but in preliminary trials, intermittent, midday misting of plants and increased drip irrigation rate resulted in reduced incidence of fruit bronzing. To characterize the bronzing phenomenon and its development in strawberry fruit tissues, we conducted an anatomical and histochemical examination of bronzed fruit. Bronzed and nonbronzed fruit were sampled over a range of fruit maturities. Results show that bronzing derives from a lesion at the cortical surface early in the fruit's development. Epidermal cells become radially compressed and the cell contents coalesce into a densely staining mass. The cuticular layer becomes disrupted and discontinuous. As the fruit develops, densely staining materials, possibly phenolic precipitates, accumulate within subepidermal cells of bronzed fruit, subepidermal cell walls thicken, and intercellular spaces fill with pectic substances and other densely staining materials. Results are consistent with reports of sunscald injury from other fruit species, and raise the possibility that strawberry bronzing occurs in response to heat or solar radiation injury.
\end{abstract}

Bronzing of strawberry fruit often occurs in late spring and summer in the central coast strawberry production region of California (lat. $\approx 36.5$ to $37^{\circ} \mathrm{N}$.), an area that produces $\approx 40 \%$ of the U.S. strawberry crop (Processing Strawberry Advisory Board of California, 2001). Symptoms consist of discoloration, desiccation, and cracking of the fruit surface. Damaged fruit is typically tan, brown or yellow-brown in color, hence the term "bronzing." The disorder occurs annually to some extent, but timing of its occurrence and severity varies from year to year. In some years, bronzing results in serious economic losses due to production of large quantities of unmarketable fruit (Larson and Sjulin, 2001).

Three distinct types of strawberry bronzing damage can be recognized (Larson and Sjulin, 2001). Type I bronzing results from feeding by westernflower thrips (Frankiniella occidentalis Pergande) or cyclamen mites (Phytonemus pallidus Banks), and typically produces damage to the fruit (receptacle) tissue around the indentations surrounding the achenes and beneath the calyx (Maas, 1998). Type II bronzing results from chemical spray burn, often as a result of application of sulfur products. In both cases, bronzing is observed in localized areas of the fruit surface that have been directly exposed to arthropod feeding or chemical contact. Type III, which typically occurs from May through July in California's central coast region, covers the entire fruit surface and is not associated with spray applications or arthropod feeding.

The occurrence of Type I and Type II bronzing is readily correlated with arthropod activity or spray applications, and is localized and episodic in nature. In contrast, Type III bronzing often occurs during extended periods in late spring and summer, a period characterized by long days, high irradiance, high temperatures, and low relative humidities. Also, Type III bronzing is observed more frequently inland than in coastal areas where lower temperatures and higher relative humidities prevail. In preliminary studies, midday microjet misting of plants and increased drip-irrigation rates resulted in reduced Type III fruit bronzing (Larson and Sjulin, 2001). Use of clear polyethylene bed mulch, applied in early winter

Received for publication 20 July 2001. Accepted for publication 29 Dec. 2001. ${ }^{1}$ Professor and corresponding author; e-mail vspolito@ucdavis.edu.

${ }^{2}$ Associate pomologist and extension specialist.

${ }^{3}$ Staff research associate. to warm the soil and enhance plant growth, also reduced Type III bronzing (Larson and Sjulin, 2001). These observations suggest that environmental and plant physiological factors may be important in development of Type III fruit bronzing.

Little is known about how Type III bronzing progresses in the strawberry fruit. In an attempt to better understand the phenomenon, we initiated the present research to characterize strawberry bronzing and its development.

\section{Materials and Methods}

'Commander' strawberry fruit exhibiting Type III bronzing symptoms and control samples that appeared to be developing normally were collected in the Watsonville, Calif., area on 2 May 2000. Collections included young fruit ( $<7 \mathrm{~d}$ postanthesis) that were sampled as early as incipient bronzing damage could be identified, midmature fruit ( 2 to 3 weeks postanthesis) with incipient bronzing symptoms evident, and full-size, unripe fruit with clear bronzing symptoms. Receptacle tissue was excised from the fruit and placed in a fixative solution of $3 \%$ glutaraldehyde and $4 \%$ sucrose in 0.025 M phosphate buffer at $\mathrm{pH} 6.8$ and stored at $4{ }^{\circ} \mathrm{C}$. The material was dehydrated in a tert-butyl alcohol series, embedded in Paraplast Plus (Sherwood Medical, St. Louis, Mo.), sectioned at a nominal thickness of $8 \mu \mathrm{m}$, and mounted in water on chrome alum-coated slides.

The sections were stained with toluidine blue $\mathrm{O}$ (Sekai, 1973) for general anatomical features. Three fluorochromes were used to determine cyto- and histochemical characteristics of cells and tissues that showed bronzing damage: coriphosphine (Ueda and Yoshioka, 1976; Weis et al., 1988) for cell-wall pectic materials, calcofluor white (Hughes and McCully, 1975) for cellulose, and nile red (Greenspan et al., 1985) for lipoidal materials. Photomicrographs were taken using a digital camera (model 750; Optronics Inc., Goleta, Calif.) on a microscope (model E600; Nikon USA, Stamford, Conn.).

\section{Results}

Incipient bronzing symptoms can be seen in young fruit within a week of anthesis. Affected fruit show slight discoloration of 
receptacle tissue. Sections of the outer cortex of sound fruit (Fig. 1A and B) and fruit showing incipient bronzing symptoms (Fig. 1C) at this stage reveal clear differences at the fruit surface. The epidermal cells of the bronzed fruit (Fig. 1C) are collapsed in the radial plane relative to sound fruit (Fig. 1A and B). These cells present a coalescence of cytoplasmic contents to form intracellular inclusions that stain densely with toluidine blue, and cell walls that are diffuse and poorly defined relative to those in sound fruit. As the fruit develops to about half of full size (Fig. 1D), bronzed fruit show increased density in the staining of the epidermal cell inclusions, and a swelling of cells walls in the subepidermal cell layers (Fig. 1D). At this stage, an amorphous material fills intercellular spaces in the subepidermal region (Fig. 1D).

In full size, unripe fruit, the outer cortical region of sound fruit is characterized by an intact epidermal cell layer that surrounds subepidermal parenchyma of large, isodiametric to slightly radially elongate, thin-walled cells with characteristic intercellular spaces (Fig. 1E). For bronzed fruit of a similar growth stage, the epidermal cells have collapsed and stain darkly (Fig. 1F). There is evidence of frequent periclinal divisions in the subepidermal parenchyma that result in formation of radial files of two to four small, somewhat tangentially elongate cells subtending the disrupted epidermis. It is not clear if this pattern results from cell division activity or failure of cells to enlarge fully. Walls of the subepidermal cells have continued to expand in thickness. Intercellular spaces become filled with material that stains positively with coriphosphine (Fig. 1G) indicating the presence of pectic materials. The coriphosphine staining pattern shows cell walls that are thickened, more diffusely stained, and less well defined relative to that seen in sound fruit (not shown) where cell walls are sharply delineated in coriphosphinestained sections. Calcofluor staining (Fig. 1H) indicates that cellulose, in contrast to pectic wall components, does not expand to fill the larger intercellular spaces, although some expansion of the fibrillar cellulose component has occurred in the walls of subepidermal cells in bronzed tissue relative to sound fruit (not shown). The intercellular spaces also stain densely with toluidine blue (Fig. 1C, $\mathrm{D}$, and F), showing a metachromatic staining reaction consistent with the presence of phenolic compounds.

Nile red produces a strong fluorescence in the presence of cuticular lipids. Its staining reaction reveals a continuous cuticle in sound young fruit (Fig. 1I). In incipiently bronzed fruit of the same age, where the epidermal cells show signs of becoming disrupted,
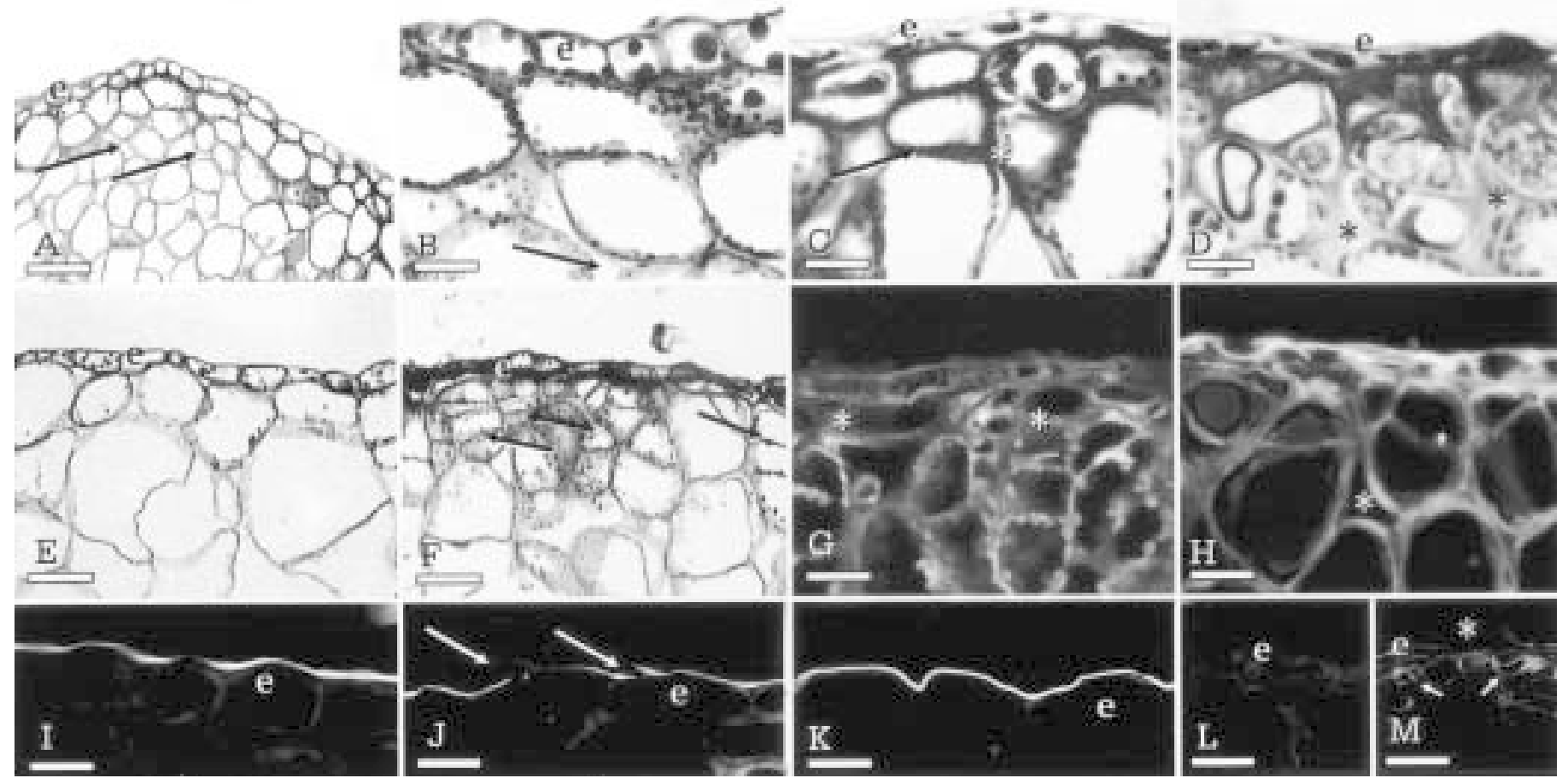

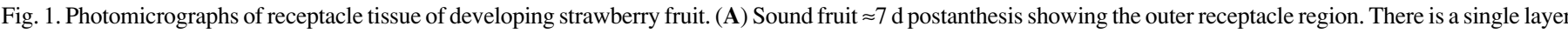
of epidermal cells (e) and subepidermal parenchyma. The parenchyma comprises thin-walled, isodiametric cells with extensive intercellular air spaces (arrow). Stained with toluidine blue O. Scale bar $=100 \mu \mathrm{m}$. (B) Same as Fig. 1A at higher magnification showing epidermal cells (e) and intercellular space in the subepidermal region

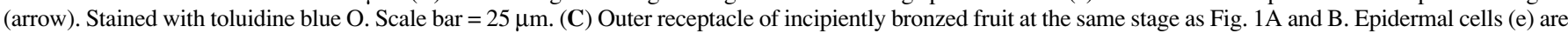
compressed in the radial plane and cell contents are coalesced into a densely staining mass. Cell walls are indistinct (arrow) relative to those in the sound fruit. Intercellular

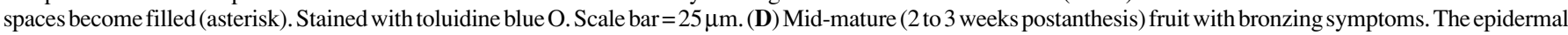
cell layer (e) is compressed and coalesced cell contents completely fill some epidermal cells. Intercellular spaces are filled (asterisk). Stained with toluidine blue O. Scale

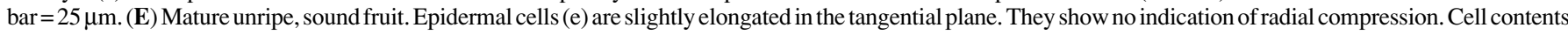
appear normal with peripheral cytoplasm and vacuoles with phenolic materials present. Subepidermal cells are isodiametric to radially elongate. Stained with toluidine

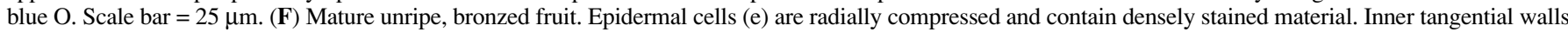

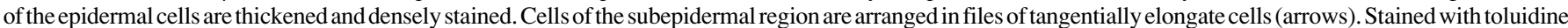

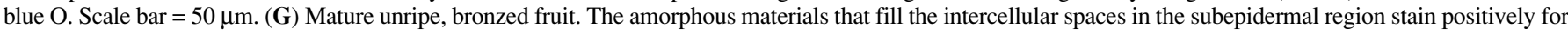
pectic materials (asterisks). Stained with coriphosphine. Scale bar $=25 \mu \mathrm{m}$. (H) Mature unripe, bronzed fruit. The amorphous materials that fill the intercellular spaces in the subepidermal region do not stain for cellulose (asterisks). Stained with calcofluor. Scale bar $=25 \mu \mathrm{m}$. (I) Young (1 week postanthesis), sound fruit. The cuticle

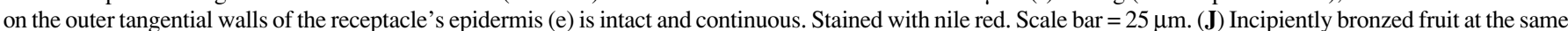
stage as Fig. 1I. The cuticle on the outer tangential walls of the receptacle's epidermis (e) shows frequent breaks and discontinuities (arrows). Stained with nile red. Scale

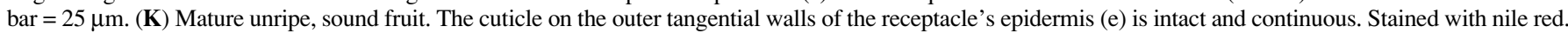

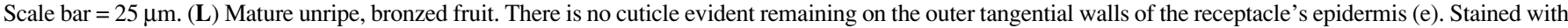

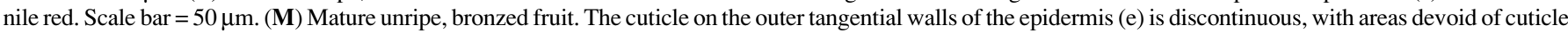
(asterisk). Subepidermal cell walls show positive staining for lipoidal substances, likely suberin (arrow). Stained with nile red. Scale bar $=100 \mu \mathrm{m}$. 
cracks and discontinuities are evident in the cuticle (Fig. 1J). In the late-stage sound fruit, the cuticle is intact on the outer tangential epidermal cell walls, and there is no positive nile-red staining reaction for matrix lipoidal materials other than the cuticle (Fig. 1K). In late-stage bronzed fruit, there are large areas of the epidermis where the cuticle is completely absent (Fig. 1L). In other areas of the fruit, the cuticle is intact only in discontinuous patches where it is thin and disrupted (Fig. 1M). Also, in bronzed fruit, there is the irregular occurrence of a positive staining reaction with nile-red in the walls of subepidermal cells, indicating deposition of lipoidal materials, likely suberin, in these walls (Fig. 1M).

Dense staining with toluidine blue $\mathrm{O}$ appears throughout the collapsed epidermis and the subepidermal cells of bronzed fruit(Fig. 1C, $\mathrm{D}$, and F). The metachromatic staining reaction is consistent with an accumulation of phenolic compounds in the damaged fruit.

\section{Discussion}

The strawberry fruit comprises an outer cortex and inner pith. The receptacle cortex does not form a distinct hypodermis beneath the epidermis, thus there is no differentiated dermal system such as that seen in many other fleshy fruits (Roth, 1977). The epidermis comprises a single layer of tangentially elongate cells. The subepidermal cells are meristematic early in the development of the receptacle and produce cortical cells by periclinal cell divisions (Havis, 1943). Authors do not agree on the timing of subepidermal meristematic activity, although a general pattern is clear. Havis (1943) found little cell division activity in the cortex after anthesis, but did note an occasional dividing cell until maturity. Knee et al. (1977) reported cell divisions in the flesh continuing for $7 \mathrm{~d}$ after petal fall, and Cheng and Breen (1992) noted some cell division activity through $15 \mathrm{~d}$ after anthesis. As the outer cortical cells enlarge, the tissue becomes parenchymatous, consisting of generally thin-walled, isodiametric, vacuolate cells. The bronzing reaction appears to be limited to these outermost cell layers of the cortex. We did not note any anomalies associated with bronzing in the cells and tissues deeper into the receptacle.

Bronzing affects the epidermal layer early in the fruit's development. By 1 week postanthesis, epidermal cells of affected fruit become radially compressed, their contents coalesce into a densely staining mass, and the outer cuticular layer becomes disrupted and discontinuous. The walls of subepidermal cells thicken. Pectic matrix materials swell and positive staining for pectin is evident in the intercellular spaces. The fibrillar cellulose component, which presents a sharply delineated line in calcofluor-stained, sound fruit, expands and acquires an indistinct profile as the wall thickens in bronzed fruit, but does not fill the intercellular space. The wall expansion and the staining reactions to coriphosphine and calcofluor that characterize the subepidermal cells of bronzed fruit are consistent with hydration and gelatinization of the pectic wall materials of these cells. In addition, there is evidence of suberization of cell walls in this region.

Densely staining materials, possibly phenolic precipitates, accumulate in the subepidermal cells. This contrasts with normal fruit development. Knee et al. (1977) conducted an ultrastructural study of the strawberry fruit and found two different types of cortical cells present at anthesis, one with densely staining intracellular materials and one without. After $7 \mathrm{~d}$ postanthesis, the density of the staining diminished and little difference in staining among cells was observed subsequent to that time. In contrast, we observed that cells with densely stained intracellular contents increase in bronzed tissue through to the mature, unripe fruit stage.
Conditions that produce this type of bronzing suggest that sunscald, or exposure to ultraviolet (UV) radiation and/or high temperatures may be involved. Recent field studies with 'Commander' strawberry, showing that midday microjet misting of plants resulted in reduced leaf temperatures and a reduction in Type III fruit bronzing (Larson and Sjulin, 2001), are consistent with this hypothesis. Little anatomical work has been reported on sunscald of fruit; however, discoloration and browning, particularly to unripe fruit surfaces, is characteristic of sunscald injury (Barber and Sharpe, 1971). Our results are consistent with the anatomical symptoms that have been seen in other fruit species. Sunscald in 'Fuji' apple [Malus sylvestris (L.) Mill. var. domestica (Borkh.) Mansf.] (Andrews and Johnson, 1997) produced anatomical changes to epidermal and subepidermal tissues comparable to what we have observed in strawberry. These included cuticle disruption, wall thickening, and accumulation of dense staining intercellular materials. Renquist et al. (1989) showed that high temperature and UV radiation injury of red raspberry (Rubus idaeus L.) druplets led to a disorder where the fruit fail to color.

Our results indicate that Type III bronzing in strawberry is a reaction to a lesion occurring in the receptacular epidermis early in fruit development that leads to loss of integrity of the epidermis and disruption of the cuticle. This lesion, likely a reaction to sunscald injury, exposure to UV radiation and/or heat stress, triggers a cascade of events in the subepidermal parenchyma marked by changes in the structure and composition of cells walls and intercellular matrix materials. The bronze coloration that characterizes injured strawberry fruit may be associated with the failure to develop normal pigmentation, accumulation of intracellular and/or matrix phenolic materials, suberization of subepidermal cell walls, or some combination of these factors.

\section{Literature Cited}

Andrews, P.K. and J.R. Johnson. 1997. Anatomical changes and antioxidant levels in the peel of sunscald damaged apple fruit. Plant Physiol. 114:103 (abstr.).

Barber, H.N. and P.J.H. Sharpe. 1971. Genetics and physiology of sunscald of fruit. Agr. Meteorol. 8:175-191.

Cheng, T.W. and P.J. Breen. 1992. Cell count and size in relation to fruit size among strawberry cultivars. J. Amer. Soc. Hort. Sci. 117:946-950.

Greenspan, P., E.P. Mayer, and S.D. Fowler. 1985. Nile red: A selective fluorescent stain for intracellular lipid droplets. J. Cell Biol. 100:965-973.

Havis, A.L. 1943. A developmental analysis of the strawberry fruit. Amer. J. Bot. 30:311-314.

Hughes, J. and M.E. McCully. 1975. The use of an optical brightener in the study of plant structure. Stain Technol. 50:319-329.

Knee, M., J.A. Sargent, and D.J. Osborne. 1977. Cell wall metabolism in developing strawberry fruit. J. Expt. Bot. 28:377-396

Larson, K.D. and T.M. Sjulin. 2001. Influence of polyethylene bed mulch, drip irrigation rate, and intermittent overhead sprinkling on strawberry fruit bronzing. HortScience 36:443 (abstr.).

Maas, J.L. (ed.). 1998. Compendium of strawberry diseases. Amer. Phytopathol. Soc., St. Paul, Minn.

Processing Strawberry Advisory Board of California. 2001. Annual report. Processing Strawberry Advisory Board of California, Watsonville.

Renquist, A.R., H.G. Hughes, and M.K. Rogoyski. 1989. Combined high temperature and ultraviolet radiation injury of red raspberry fruit. HortScience 24:597-599.

Roth, I. 1977. Fruits of angiosperms. Gebrüder Borntraeger. Berlin-Stuttgart.

Sekai, W.S. 1973. Simple method for differential staining of paraffin embedded plant material using toluidine blue O. Stain Technol. 48:247-249.

Ueda, K. and S. Yoshioka. 1976. Cell wall development of Micrasterias americana, especially in isotonic and hypertonic solutions. J. Cell Sci. 21:617.

Weis, K.G., V.S. Polito, and J.M. Labavitch 1988. Microfluorometry of pectic materials in the dehiscence zone of almond [Prunus dulcis (Mill.) D.A. Webb] fruit. J. Histochem. Cytochem. 36:1037-1041. 